\title{
Interactive comment on "A new 30,000 year chronology for rapidly deposited sediments on the Lomonosov Ridge using bulk radiocarbon dating and probabilistic stratigraphic alignment" by Francesco Muschitiello et al.
}

Francesco Muschitiello et al.

fm476@cam.ac.uk

Received and published: 15 February 2020

First, we would like to thank Reviewer 1 for the time he/she/they took to review our study and for their constructive criticism. His/her/their comments have helped us to craft a revised and more rigorous version of our manuscript. Please find below a detailed point-by-point response to the "Reviewer's comments". ers for the nearby PS2471-1 core is critical since MIS $330-40 \mathrm{ka}$ seems to be a very 
warm interstadial period with abundant calcareous preservation throughout the Arctic. I would thus like to see more paleoceanographic interpretation of this time period. This especially applies not only to MIS 3, but older and younger to paleo-sea ice reconstructions from PS2471-1."

We thank Reviewer 1 for his/her/their comment. Following this commentary, we have now included a more comprehensive discussion as to the implications of our new age model and the re-interpretation of the sea-ice reconstructions presented by Xiao et al. (2015) from MIS-2 to the Holocene. In particular, we now stress upfront that our new chronology implies that the sedimentary sequence recovered in PS2767-4 was entirely deposited during MIS-2, the deglaciation, and the Holocene, and therefore should no longer be interpreted as containing a continuous or partial record of MIS-3. Please see section 3.3 of the revised manuscript (new lines 235-267).

"In addition, How does the age reinterpretation affect ideas about glacial maximum sea ice and ice shelf from other regions and ridges in the central Arctic Ocean?"

Please see our previous reply. We have now provided a more detailed interpretation of the sea-ice reconstruction from the central Arctic Ocean in light of our new marine chronology. We also present a new figure (Figure 5) illustrating the re-interpretation of the sea-ice biomarkers records grouped by time intervals (i.e. Holocene, deglaciation, and LGM/MIS-2). Please see section 3.3 of the revised manuscript (new lines 253-267) and Figure 5.

"Finally, the alignment of the GISP ice core and 312PC porosity data in Fig 3 is impressive, a more extended discussion of the paleoclimatology and climate dynamics of this near synchroneity is needed."

Thank you for bringing this up. We would like to point out that pinning down the precise physical mechanism linking Greenland climate and changes in sedimentary and/or proxy parameters in marine records remains to this date a challenging task, and any explanation should be considered as speculative. This is the case for the large majority of 
marine chronologies that lack robust age constraints and hinge on alignment between a given proxy record and far afield hydro-climate changes as recorded in Greenland ice cores, or other absolutely dated climate records (e.g. Hulu Cave). However, to address the reviewer's comments, we now provide a tentative explanation for such a link. We speculate that fluctuations in high-latitude hydro-climate -as recorded in Greenland ice-core records- may have driven large-scale changes in Arctic fluvial runoff and subsequent flux of sediment to the Arctic Ocean, which was ultimately integrated in the porosity profile of our sedimentary record. Please see new lines 121-125.

"Specific minor comments on page 3 l'd like to see a little more discussion of the concerns about changing delta $R$ values. It also says fossil content is minor, can you expand what you mean? No forams? Ostracodes? Few molluscs for dating?"

Thank you for this comment. We have now included additional discussion as to why we deem a $\Delta \mathrm{R}$ uncertainty of $-400 /+1000$ years appropriate for the one early Holocene mollusc sample. Specifically, we argue that this choice is likely very conservative for the following reasons. On one hand, a lower $\Delta \mathrm{R}$ bound of -400 implies no reservoir correction (i.e. the $14 \mathrm{C}$ age of the sample nearly approaches that of the contemporaneous atmosphere at time of deposition), and on the other hand, an upper bound of +1000 is considerably higher than the widely used correction for this region (e.g. Bauch et al., 2001) that is $-30+/-49$ years (i.e. $R=370+/-49$ years). In addition, it should be noted that independent $\Delta R$ reconstructions of intermediate waters leaving the Nordic Seas and feeding into the Arctic Ocean indicate values ranging $\sim 0$ years during the late Younger Dryas stadial and early Holocene (Muschitiello et al., 2019), which is in line with modern estimates for the central Arctic Ocean and the $\Delta R$ adjustment that is generally applied to $14 \mathrm{C}$ chronologies from this area. These points are now presented in Section 2.3 (new lines 87-95). We have also clarified that no foraminifera, molluscs or ostracodes were found for radiocarbon dating (new line 80). 
Bauch, H. A., Mueller-Lupp, T., Taldenkova, E., Spielhagen, R. F., Kassens, H., Grootes, P. M., Thiede, J., Heinemeier, J. and Petryashov, V. V: Chronology of the Holocene transgression at the North Siberian margin, Glob. Planet. Change, 31(1-4), 125-139, 2001.

Muschitiello, F., D’Andrea, W. J., Schmittner, A., Heaton, T. J., Balascio, N. L., deRoberts, N., Caffee, M. W., Woodruff, T. E., Welten, K. C., Skinner, L. C., Simon, M. H. and Dokken, T. M.: Deep-water circulation changes lead North Atlantic climate during deglaciation, Nat. Commun., doi:10.1038/s41467-019-09237-3, 2019.

Xiao, X., Stein, R. and Fahl, K.: MIS 3 to MIS 1 temporal and LGM spatial variability in Arctic Ocean sea ice cover: Reconstruction from biomarkers, Paleoceanography, 30, doi:10.1002/2015PA002814, 2015.

Interactive comment on Geochronology Discuss., https://doi.org/10.5194/gchron-2019-16, 2019. 